\title{
A Descriptive Study to Assess the Quality of Life of Patient with Type 2 Diabetes Mellitus in a Selected Rural Community at Kancheepuram District Tamil Nadu, India
}

\author{
S. Kamali ${ }^{1}$, Kavitha Jasmine ${ }^{1}$, A. Jaya, M. Janani ${ }^{1}$, \\ S. Kamali ${ }^{1}$, Kavitha Jasmine ${ }^{1}$, A. Jaya ${ }^{1}$, M. Janani ${ }^{1}$, Shenbagapraba N. ${ }^{2}$ \\ ${ }^{1}$ III Year B.Sc. Nursing, ${ }^{2}$ Assistant Professor, Department of Community Health Nursing, Chettiand College of \\ Nursing, Chettinad Academy of Research and Education, Kelambakkam, Kanchipuram District,Tamil Nadu, India
}

\begin{abstract}
Diabetic 2 mellitus is also known as non-insulin dependent diabetic mellitus. It is associated with abnormalities in carbohydrate, fat and protein metabolism and may result in the chronic complication including micro vascular, macro vascular and neuropathic disorders. The reality is that diabetes influences patients' lives. The mere presence of diabetes deteriorates a person's quality of life. When diabetes coexists with other chronic illnesses the effect is even worse. The objectives of the study is to assess the quality of life of type 2 diabetes mellitus patient in a selected rural area and association between the quality of life and the demographic variables. A purposive sampling technique is used to collect drug from the samples. The sample size was 93 type 2 diabetes patients at selected rural community area. The quality of life was assessed by final quolid questionnaires. The result shows that $6(6 \%)$ of sample had low level of quality of life, $79(85 \%)$ of the sample had average level of quality of life, $8(9 \%)$ of sample had high level of quality of life.
\end{abstract}

Keywords: Assess, type 2 diabetes mellitus, quality of life.

\section{Introduction}

Type 2 Diabetic mellitus is result from a decrease in the sensitivity of the cells to insulin and decreased in the amount of insulin produced. Diabetic 2 mellitus is also known as non-insulin dependent diabetic mellitus. ${ }^{1}$

The reality is that diabetes influences patients' lives. The presence of diabetes deteriorates a person's quality of life. When diabetes coexists with other chronic illnesses the effect is even worse. The worldwide interest is reflected on the 1950000 articles and reviews published in the last five years on diabetic complication

\footnotetext{
Corresponding Author:

Shenbagapraba $\mathbf{N}$.

Assistant Professor, Chettinad Health City, Chettiand

College of Nursing, Rajiv Gandhi Salai, Kelambakkam, Kanchipuram District, Tamil Nadu, India-603103

e-mail: shenbagamae83@gmail.com

Phone Number: 9789105190/04447429021
}

are between 15000 and $28000^{2}$. Notably only one article was found to assess family functioning. Due to population growth, aging, urbanization and increasing prevalence of physical inactivity and obesity the risk of diabetes continues to increase worldwide. The highest rate of diabetes prevalence in the world is in the Middle east and north Africa was recently said by international diabetes federation. In this region about $12.5 \%$ of adults aged 20-79 years or 32.8 million people had diabetes in 2011 year and this number is expected to double in less than 20 years. ${ }^{1}$

\section{Material and Method}

Research Design: Descriptive design

Research Approach: Non experimental study

Research Setting: The study to conduct in a selected rural community.

Population: It includes type 2 diabetes mellitus patient in a selected rural community. 
Sample Size: $n=[D E F F * N p(1-p)] /\left[\left(d^{2 /} Z^{2} 1{ }_{-\alpha / 2}{ }^{*}\right.\right.$ $\left.(\mathrm{N}-1)+\mathrm{p}^{*}(1-\mathrm{p})\right] 93$ samples

Sampling Technique: Purposive sampling technique.

\section{Findings:}

Section-A: Frequency and percentage distribution of demographic variables to assess the quality of life of Type 2 diabetes mellitus among type 2 diabetes mellitus patient in Poonchery.

- Gender: Majority of $55(59 \%)$ of population belongs to male and $38(41 \%)$ of population belongs to female

- Age: Majority of 37(40\%) of the population belongs to the age $55-65 \mathrm{yrs}$ and $36(39 \%)$ of the population belongs to the age $45-54 \mathrm{yrs}, 20(22 \%)$ of the population belongs to the age 35-44.

- Education: Majority 39(42\%) of the population completed primary education $\left(1^{\text {st }}-4^{\text {th }}\right), 35(38 \%)$ of the population are illiterate, $15(16 \%)$ of the population completed secondary $\left(6^{\text {th }}-7^{\text {th }}\right),(4-4 \%)$ of the population completed higher secondary $\left(8^{\text {th }}\right.$ $\left.12^{\text {th }}\right)$.

- Occupation: Majority 35(37\%) of the population are self-employee, $16(20 \%)$ of the population were daily wage, $15(16 \%)$ of the population were private employee, $25(27 \%)$ of the population were house wife.

- Family Monthly Income: Majority of 49(53\%) of the population earn below Rs5000 and 40(43\%) of the population earn above Rs5001-10,000 and $2(2 \%)$ of the population earn above $10,001-15,000$, and $2(2 \%)$ of the population earn 15,001 and above

- Types of Family: Majority of $57(61 \%)$ of the population are nuclear,36(39\%) of the population are joint

- Marital Status: Majority of $87(94 \%)$ of the population are married, $6(6 \%)$ of the population are unmarried

- Duration of Diabetes: Majority of $43(46 \%)$ of the population were $0-5$ years, $42(45 \%)$ of the population were $5-10$ years, $8(8 \%)$ of the population were above 10 years

- Types of Medication: Majority of 54(58\%) of the population take OHA, 18(19\%) of the population are insulin, 13(14\%) of the population were in $\mathrm{OHA}+$ insulin, $8(8 \%)$ of the population were life style

- Sources of Information: Majority of 88(95\%) of the population get information from health personnel,5(5\%) of the population were by friends.

Section-B: Distribution of knowledge on quality of life of Type 2 diabetes mellitus among type 2 diabetes mellitus patient in Poonchery.

It shows that mean percentage (53.97) and standard deviation (21.24) aspect of quality of life of type 2 diabetes mellitus patient. Overall mean in the quality of life among $\mathrm{n}=93$ type 2 diabetes mellitus patient found to be (21.24) and according to the quality of life of type 2 diabetes mellitus patient $6(6 \%)$ of population were in low level, $79(85 \%)$ of population were in average level, $8(9 \%)$ of population were in high level.

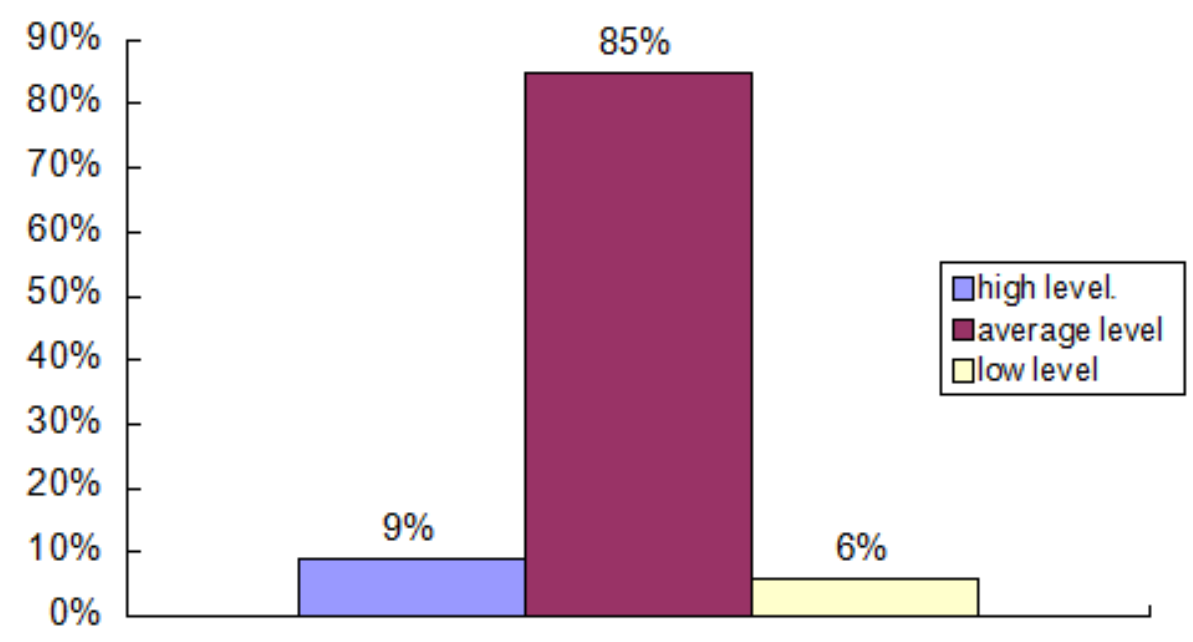

Fig. 1: Distribution of knowledge on quality of life of Type 2 diabetes mellitus among type 2 diabetes mellitus patient in Poonchery 
Section C: Association of level of knowledge on quality of life type 2 diabetes mellitus with the demographic variables:

Regarding association shows that the education, family monthly income, duration of diabetes and type of medication is significant and the gender, age, occupation, type of family, marital status and source of information is non-significant with quality of life of patient in type 2 diabetes mellitus.

Summary: This chapter deals with the analysis and interpretation of the collected data from the quality of life of type 2 diabetes mellitus patient. The data collected was tabulated and analyzed using descriptive and inferential statistics, frequency and percentage were compared to summarize the sample characteristics. Mean, mean percentage and chi square were used to compare the quality of life.

Source of Funding: Nil

Ethical Consideration: Chettinad Academy of Research and Education Institution Human Ethics Committee

\section{Conflict of Interest: Nil}

\section{Reference}

1. Harish Kumar somappa. Quality of life of assessment among type 2 diabetic patient in rural teritary center. International journal of science and public health 2014; 3(4): 415-417. (accessed 26.03.2014).

2. Harsimran sing, clarebradley. Quality of life in diabetes. Int j diabdevctries 2006; 28(1).

3. Manjunath k et.al. Quality of life of a patient with type 2 diabetes; a cross sectional study in rural south india. Journal of family medicine and primary care 2014; 3(4): 396-399.

4. Jitendernagpalet.al . The development of quality of life instrument for Indian diabetes patient (QOLID). The journal of the association of physicians of indiaMay 2010; 58(5): 295-304.

5. Praveen kumar, Manu krishna. Quality of life in diabetes mellitus. Science journal of public health 2015; 3(3): 310-313. 